\title{
Epitaxial III-V films and surfaces for photoelectrocatalysis
}

\author{
Henning Döscher ${ }^{*[a, b]}$, Oliver Supplie ${ }^{[a]}$, Matthias M. May ${ }^{[a]}$, Philipp Sippel ${ }^{[a]}$, \\ Christian Heine ${ }^{[\mathrm{a}]}$, Andrés G. Muñoz ${ }^{[\mathrm{a}]}$, Rainer Eichberger ${ }^{[\mathrm{a}]}$, Hans-Joachim \\ Lewerenz $^{[a]}$, and Thomas Hannappel ${ }^{[a, b]}$
}

((Dedication, optional))

Efficient water splitting photoelectrochemical devices benefit from highest material quality and dedicated surface preparation achieved by epitaxial growth. InP(100) based half-cells show significant solarto-hydrogen efficiencies, but require a bias due to insufficient voltage. Tandem absorber structures may provide both adequate potential and efficient utilization of the solar spectrum. We propose epitaxial dilute nitride GaPNAs photocathodes on Si(100) substrates to combine close-to-optimum limiting efficiency, lattice-matched growth, and established surface preparation. Prior to a discussion of the challenging III-V/Si(100) heterojunction, we describe the closely related epitaxial preparation of $\ln P(100)$ surfaces and its beneficial impact on photoelectrochemical water splitting performance. Analogies and specific differences to $G a P(100)$ surfaces are discussed based on in situ reflectance anisotropy and on 2-photon photoemission results. Preliminary experiments regarding $\mathrm{GaP} / \mathrm{Si}(100)$ photoelectrochemistry and dilute nitride GaPN heteroepitaxy on Si(100) confirm the potential of the GaPNAs/Si tandem absorber structure for future water splitting devices.

\section{Introduction}

Renewable energy research is of utmost importance for the development of a long-term, sustainable energy economy. Both demand and supply of renewable power are subject to strong fluctuations. Hence, the ability to store electricity on large scales is a crucial technological issue. Direct photoelectrochemical water splitting ${ }^{[1]}$ combines the harvesting of solar energy and the electrolysis of water in a single device. Substantial solar-tohydrogen efficiencies above $12 \%{ }^{[2]}$ were achieved with an integrated device based on the epitaxial $\mathrm{GalnP}_{2} / \mathrm{GaAs}$ tandem photovoltaic cell ${ }^{[3]}$ more than a decade ago. In spite of intense research effort on alternative materials for cost-efficient renewable solar fuel generation by direct photoelectrolysis, the desired technological breakthrough is still obstructed by the diversity and complexity of interrelated key criteria ${ }^{[4]}$.

I. Efficiency in the utilization of the solar spectrum;

II. Sufficiency of the generated voltage for water splitting;

III. Matching of the surface band edge potentials with hydrogen and oxygen redox potentials;

IV. Long-term stability in aqueous electrolytes;

V. Selectivity of the charge transfer promoting water splitting over corrosion reactions.

III-V materials enable world-record solar-to-hydrogen efficiencies ${ }^{[2]}$, but are subject to degradation. Dilute nitride incorporation may improve the stability in contact with an electrolyte ${ }^{[5]}$. InP based half-cell arrangements show significant

hydrogen evolution efficiency ${ }^{[6]}$, but require an external bias to complement the insufficient voltage. In this paper, we propose an epitaxial dilute nitride $\mathrm{GaPN} / \mathrm{Si}(100)$ tandem absorber structure for a solar water splitting device. We begin our discussion with a general evaluation of multi-junction absorber structures and of their epitaxial design showing the high potential benefit of our approach. Since GaPN surface structure and preparation are closely related to those of well-established InP photocathodes, we first describe the successful utilization of epitaxial $\ln P$ strutures for electrochemical water splitting before turning to the challenging heteroepitaxial integration of $\mathrm{GaP}$ on $\mathrm{Si}(100)$ substrates. We show preliminary photoelectrochemistry results with $\mathrm{GaP} / \mathrm{Si}$ structures and describe the growth of the dilute nitride GaPN lattice matched to $\mathrm{Si}(100)$.

[a] Dr. H. Döscher, O. Supplie, M.M. May, P. Sippel, C. Heine, Dr. A.G. Munoz, Dr. R. Eichberger, Prof. H.-J. Lewerenz, Prof. Hannappel Institut für Solare Brennstoffe und Energiespeichermaterialien Helmholtz-Zentrum Berlin für Materialien und Energie Hahn-Meitner-Platz 1 14109 Berlin (Germany)

Fax: $(+49)(0) 30-8062-42434$

E-mail: henning.doescher@helmholtz-berlin.de

[b] Dr. H. Döscher, Prof. T. Hannappel

Institut für Physik

Technische Universität IImenau

Weimarer Str. 25

98693 IImenau (Germany) 


\section{Results and Discussion}

Photovoltaic devices enable renewable power supply by direct conversion of solar radiation into electric energy. Light absorption in semiconductor materials generates electron-hole pairs, which can be separated by $\mathrm{p} / \mathrm{n}$-junctions. In principle, the conversion efficiency is optimized by matching the band gap of the utilized semiconductors with the continuous distribution of photon energies in the solar spectrum. Transmission of the radiation occurs below the band gap, while almost immediate thermalization of the excited charge carriers after photon absorption essentially confines the yield per photon below the band gap energy. Detailed balance calculations ${ }^{[7]}$ specify an upper theoretical limit for the conversion efficiency of a conventional single-junction solar cell with about $30 \%$.

With $1.12 \mathrm{eV}$, the band gap of silicon is already close to the required optimum, but below the energetic barrier of $1.23 \mathrm{eV}$ for water oxidation. Considering kinetic overpotentials required to drive the photoelectrocatalytical reaction and other inevitable loss mechanisms, a voltage of $2.0 \mathrm{~V}$ is generally considered as the minimum requirement for a water splitting device ${ }^{[8]}$. In an idealized single-junction configuration, the necessity of $2.0 \mathrm{eV}$ band gap translates to a significant drop of the theoretical maximum of the solar cell conversion efficiency due to the inability to absorb a major share of the solar spectrum.

\section{Multi-junction absorber structures}

In photovoltaics, the theoretical limitation of overall conversion efficiencies can be increased significantly, when the light transmitted through an individual solar cell is absorbed by a subsequent one with a lower band gap. Monolithic multi-junction devices based on epitaxial subcells connected by a tunnel junction ${ }^{[3]}$ have already achieved conversion efficiencies significantly above $40 \%$ under concentrated sunlight today ${ }^{[9]}$ Serial connection of the individual subcells implies limitation of the whole device by the subcell generating the smallest photocurrent. Tandem absorber structures combine efficient use of the solar spectrum with sufficient voltage for water splitting devices without excessive overpotential. We calculated the limiting efficiencies and optimum band gap energies of multijunction solar cells with EtaOpt ${ }^{[10]}$

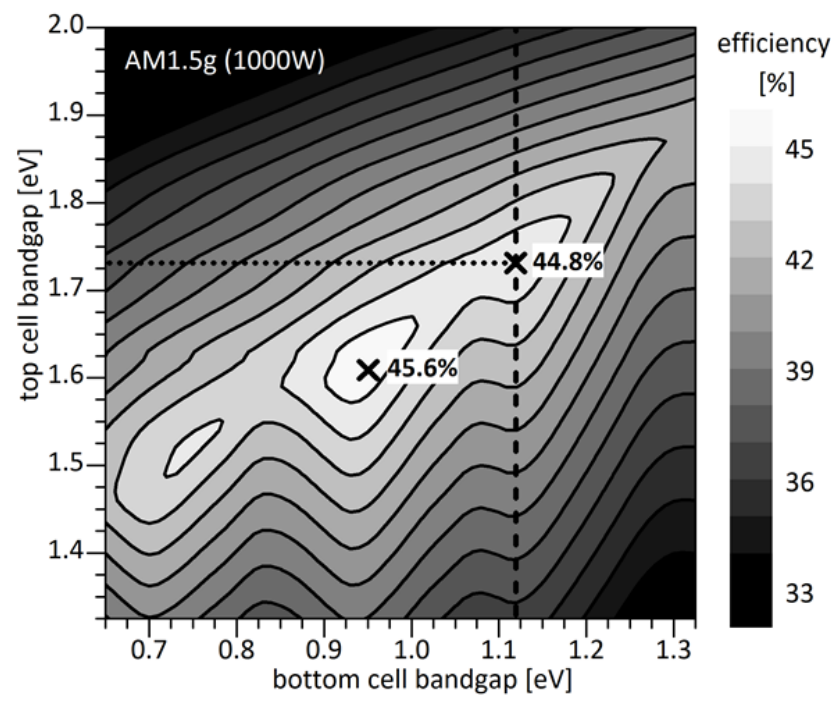

Figure 1. Contour lines of calculated limiting conversion efficiencies for ideal monolithic tandem solar cells under AM1.5g irradiation (1000W, one sun) at ambient temperature in dependence of top and bottom cell band gap.

Figure 1 shows a contour plot for a tandem configuration involving two arbitrary band gaps, where the contour plot represents the theoretical limiting conversion efficiency for standardized terrestrial solar radiation in dependence of both band gap energies. Hydrogen generation efficiency does not necessarily scale with solar cell power, but depends on both voltage (threshold) and current (rate) rather independently. Nevertheless, the theoretical efficiency limits shown in Table 1 may help to compare the principal potential of different cell concepts.

\begin{tabular}{|c|c|c|c|}
\hline Type of solar cell & $\begin{array}{l}\text { Band gap } \\
\text { (top cell) }\end{array}$ & $\begin{array}{l}\text { Band gap } \\
\text { (bottom cell) }\end{array}$ & $\begin{array}{l}\text { Limiting } \\
\text { efficiency }{ }^{\text {[a] }}\end{array}$ \\
\hline Optimum single junction & $1.16 \mathrm{eV}$ & --- & $33.7 \%$ \\
\hline Silicon (single junction) & $1.12 \mathrm{eV}$ & --- & $33.5 \%$ \\
\hline Water splitting minimum ${ }^{[b]}$ & $2.00 \mathrm{eV}$ & --- & $23.0 \%$ \\
\hline Optimum tandem & $1.61 \mathrm{eV}$ & $0.95 \mathrm{eV}$ & $45.6 \%$ \\
\hline InGaP $2 / G a A s$ tandem ${ }^{[c, d]}$ & $1.83 \mathrm{eV}$ & $1.42 \mathrm{eV}$ & $38.5 \%$ \\
\hline GaPN/Si tandem & $1.95 \mathrm{eV}$ & $1.12 \mathrm{eV}$ & $37.2 \%$ \\
\hline GaPNAs/Si (optimum) & $1.73 \mathrm{eV}$ & $1.12 \mathrm{eV}$ & $44.8 \%$ \\
\hline
\end{tabular}

The limiting solar cell efficiency of the $\operatorname{lnGaP}_{2} / \mathrm{GaAs}$ combination of $38.5 \%$ only partially realizes the theoretical potential of $45.6 \%$ for tandem cells due to rather high band gaps. The value of $1.12 \mathrm{eV}$ of $\mathrm{Si}$ is still clearly above the optimum band gap energy of $0.95 \mathrm{eV}$ for the bottom cell of a tandem, but a close-to-optimum efficiency limitation of $44.8 \%$ is achieved in combination with a $1.73 \mathrm{eV}$ band gap top cell (Figure 1). A disproportionally higher increase of hydrogen generation efficiency could be expected due to the simultaneous reduction of overpotentials. The dilute nitride III-V material system appears very promising for both dedicated band gap engineering and epitaxial integration on Si substrates.

\section{Epitaxial design of III-V heterostructures}

Present high-efficiency multi-junction solar cells typically consist of two different III-V semiconductor subcells grown by metalorganic vapor phase epitaxy (MOVPE) on $\mathrm{Ge}(100)$ substrates. In general, the growth of ternary and higher order III-V compounds enables both dedicated band gap engineering and combinations of different band gap energies according to the desired applications. However, preserving highest epitaxial quality in a device structure usually requires maintaining the lattice constant of the substrate. 


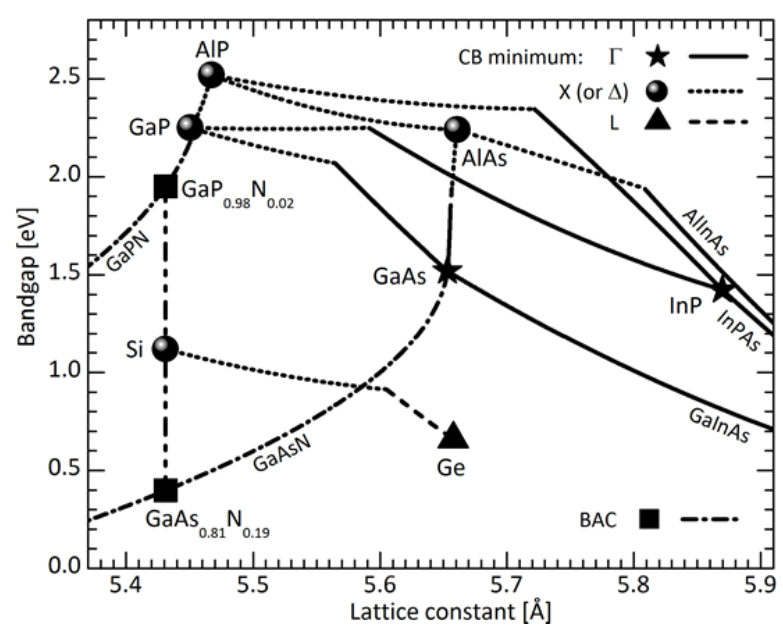

Figure 2. Band gap energies of elemental and III-V compound semiconductors over lattice constants. Solid and dashed lines indicate ternary III-V materials. The enclosed area indicates properties achievable with quarternary or higher order compounds. Dilute nitrogen incorporation in $\mathrm{GaP}$ and $\mathrm{GaAs}$ extends the range of materials combinations significantly, particularly enabling the growth of lattice matched III-V heterostructures on Si substrates.

Figure 2 shows the band gap energies of elemental ( $\mathrm{Si}, \mathrm{Ge}$ ) and classical III-V compound (GaAs, InP etc.) semiconductors plotted over the associated lattice constants. While the lattice constants of both binary (SiGe) and ternary (III-V) alloys have been derived directly by Vegard's law, additional bowing parameters have to be considered for their band gap energies. Our evaluation based on the data published in Refs. ${ }^{[11]}$ for III-Vs and ${ }^{[12]}$ for SiGe as well as on the band anti-crossing (BAC) model ${ }^{[13]}$ for $\mathrm{GaAsN}$ and $\mathrm{GaPN}{ }^{[14]}$. Dilute nitride incorporation strongly reduces the band gap of III-V-N alloys. The BAC model explains the experimental observation with a spatially located nitrogen level $E_{N}$ interacting with the conduction band $E_{C}(k)$ of the host material ${ }^{[13]}$, which induces a splitting of the conduction band.

Although the accuracy of the BAC results may be disputed ${ }^{[14]}$, Figure 2 clearly shows the capability to grow lattice matched dilute nitride III-V compounds with band gaps in the crucial range of $1.95-1.60 \mathrm{eV}$ and optimized solar light absorption properties on Si substrates. Over the last decades, intense III-V/Si research was mainly triggered by technological interests of the microelectronics industry in the superior electronic and optoelectronic properties of III-V semiconductors ${ }^{[15]}$. However, severe issues are induced by the deviation of basic material parameters such as lattice constants (Figure 2) and thermal expansion coefficients as well as by the formation of the crucial polar-on-non-polar interface, which we discuss below.

\section{$\ln \mathrm{P}(100)$ surface preparation}

Due to its direct bandgap and high electron mobility, InP draw large interest regarding optoelectronic devices. InP is widely used as substrate for lasing heterostructures in the communication wavelength regime ${ }^{[16]}$ and multi-junction solar cells ${ }^{[17]}$. Also the first efficient photocathodes for hydrogen evolution were based on $p-\ln P(111) A$ wafers ${ }^{[6]}$. Here, we focus on the atomic surface properties of (100) surfaces of homoepitaxial InP buffer layers, which have recently been applied for solar-to-hydrogen conversion ${ }^{[18]}$.
Based on the combined results of theoretical calculations, of experimental surface science investigations in UHV, and of in situ RAS data measured in MOVPE ambient, a direct identification between characteristic RA spectra and the surface reconstructions of $\operatorname{In} \mathrm{P}(100)$ have been established. Monitoring the transition between P-rich and In-rich surface reconstructions ${ }^{[19]}$ permits precise in situ control over the surface preparation. After transfer to UHV, both band structure ${ }^{[20]}$ and femtosecond carrier dynamics ${ }^{[21]}$ of MOVPE-prepared $\operatorname{InP}(100)$ surfaces have been studied in detail. The P-rich surface reconstruction typical for MOVPE-prepared $\operatorname{InP}(100)$ is based on a (2x2) unit cell (inset in Figure 3a) containing two $P$ dimers buckled in opposite directions. Since each of those are stabilized by one hydrogen atom saturating one of the dangling bonds this surface is referred to as $(2 \times 2)-2 \mathrm{D}-2 \mathrm{H}$ in theory publications ${ }^{[22]}$. While the reconstruction is highly ordered along the phosphorus dimer rows, phase shifts with the periodicity of half a unit cell can occur in adjacent rows leading to a coexistence of areas with $(2 \times 2)$ and $\mathrm{c}(4 \times 2)$ symmetry visible in STM observations ${ }^{[23]}$. In contrast, LEED does only show an averaged (2x1)-like diffraction pattern with additional streaks. Recently, Kleinschmidt et al. have reported about flip-flop motion of the terminal hydrogen atom on the MOVPE-prepared P-rich $\operatorname{InP}(100)$ surface observed by STM after transfer to UHV ${ }^{[24]}$. Annealing above the incongruent desorption temperature of $638 \mathrm{~K}^{[25]}$ without precursor supply leads to a disproportional loss of $P$ from the $\ln P(100)$ surface eventually inducing In droplet formation. According to theoretical stability predictions ${ }^{[26]}$, a $(2 \times 4)$ structure terminated with a single mixed $(\mathrm{P}-\mathrm{In})$ dimer per unit cell (inset in Figure $3 a)$ is considered as the most In-rich surface reconstruction of $\ln P(100)$. The mixed dimer model is consistent with experimental investigations of Inrich MOVPE-prepared $\operatorname{InP}(100){ }^{[26]}$ showing a $(2 \times 4)$ LEED pattern and row-like structures in STM images ${ }^{[27]}$.
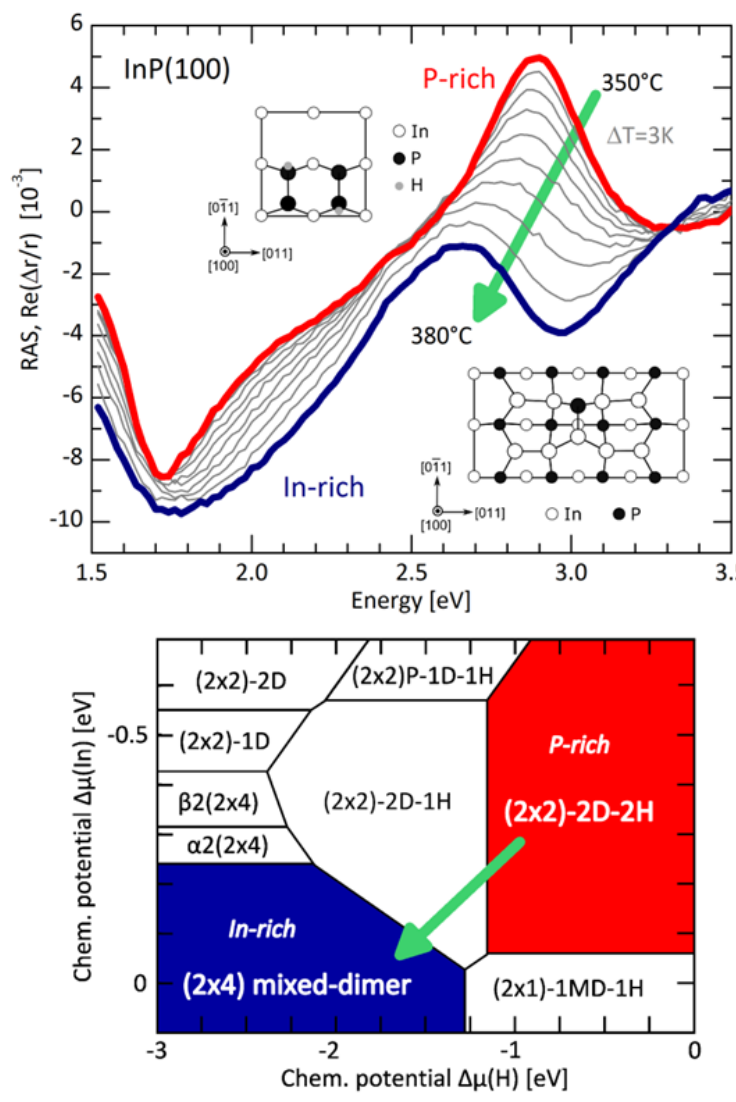
Figure 3. (a) In situ RA spectra of $\operatorname{InP}(100)$ measured continuously while the sample temperature was ramped up at a rate of $1.5 \mathrm{~K} / \mathrm{min}$ without TBP supply. Desorption of phosphorus at temperatures between $350^{\circ} \mathrm{C}$ and $380^{\circ} \mathrm{C}$ leads to a transition from the P-rich to the $\operatorname{In}$-rich $\ln \mathrm{P}(100)$ surface. (b) Calculated phase diagram of the hydrogen exposed $\ln P(100)$ surfaces after Ref. ${ }^{[22]}$ where $\Delta \mu(H)$ is given in reference to molecular hydrogen. The P-rich configuration typical for MOVPE preparation (red), the In-rich mixed-dimer surface can be prepared by cycled annealing without TBP supply (blue)

Figure 3(a) shows the RAS monitoring of the transition from the P-rich to the In-rich $\operatorname{InP}(100)$ surface in hydrogen ambient. Therefore, an $\ln \mathrm{P}(100)$ wafer was thermally deoxidized and homoepitaxially overgrown with an $\operatorname{InP}$ buffer layer at $575^{\circ} \mathrm{C}$. To prepare the P-rich surface, the sample was cooled under TBP supply to $300^{\circ} \mathrm{C}$. TBP was then switched off and the sample was annealed in hydrogen ambient with a $1.5 \mathrm{~K} / \mathrm{min}$ temperature ramp. Precursor residuals and physisorbed excess phosphorus desorbs at about $360^{\circ} \mathrm{C}$ and the P-rich surface develops. RAS is very sensitive regarding the atomic order on the surface as demonstrated by the fine-tuning of the P-rich surface by Letzig et al. ${ }^{[28]}$ Further annealing from $350^{\circ} \mathrm{C}$ to $380^{\circ} \mathrm{C}$ leads to continuous phosphorus desorption and formation of the $\ln$-rich $\operatorname{InP}(100)$ surface. During that transition, the RA spectrum transforms accordingly (grey lines in Figure 6). Schmidt et al. calculated formation energies for the different surface reconstructions [26] and the phase diagram for the $\ln \mathrm{P}(100)$ surface exposed to hydrogen ${ }^{[22]}$, which is shown in in Figure $3(\mathrm{~b})$ with red and blue highlighted phases for the P-rich and the In-rich $\operatorname{InP}(100)$ surface, respectively. During MOVPE preparation, the chemical potentials are determined by the surface temperature of the sample and the chemical environment defined by the choice of process gas. The RAS signal of the In-rich $\operatorname{InP}(100)$ surface features a broader minimum at about $2 \mathrm{eV}$ and, in strong contrast to the P-rich surface, another minimum at the $\mathrm{E} 1$ interband transition. The differences in lineshape and amplitude of the spectra of P-rich and $\ln$-rich $\ln P(100)$ surface enable direct in situ identification of the different reconstructions.

\section{Hydrogen generation with epitaxial $\ln \mathrm{P}(100)$ structures}

Water splitting applications benefit from well-defined material quality and, in particular, from dedicated surface preparation enabled by MOVPE. We grew p-type material on $\operatorname{InP}(100)$ substrates and prepared the In-rich mixed-dimer $(2 \times 4)$ surface reconstruction showing virtually no photoactivity after growth or after a methanol bromine etch. A photoactivation is observed in situ when the samples are cyclically polarized in $\mathrm{HCl}$ between potential limits where reduction- as well as oxidation processes occur. The basic anodic and cathodic corrosion processes are (anodic processes, $V^{0}$ vs. SCE)

$$
\begin{array}{ll}
2 \mathrm{In}+6 h^{+}+3 \mathrm{H}_{2} \mathrm{O} \rightarrow \mathrm{In}_{2} \mathrm{O}_{3}+6 \mathrm{H}_{a q}^{+} & V^{0}=-0.41 \mathrm{~V} \\
3 \mathrm{InP}+15 \mathrm{H}_{2} \mathrm{O}+24 h^{+} \rightarrow \operatorname{In}\left(\mathrm{PO}_{3}\right)_{3}+2 \mathrm{In}(\mathrm{OH})_{3}+24 \mathrm{H}_{a q}^{+} & V^{0}=-0.84 \mathrm{~V} \\
\mathrm{InP}+4 \mathrm{H}_{2} \mathrm{O}+8 h^{+} \rightarrow \mathrm{InPO}_{4}+8 \mathrm{H}_{a q}^{+} & V^{0}=-0.92 \mathrm{~V} \\
\quad \text { and (cathodic process) } & \\
p-\operatorname{InP}+3 e_{C B}^{-}(h v)+3 \mathrm{H}_{a q}^{+} \Rightarrow \mathrm{In}^{0}+\mathrm{PH}_{3} &
\end{array}
$$

There is a further possibility to form indium monochloride which was identified in experiments on InP photocathodes that operated in the photovoltaic mode of a photoelectrochemical solar cell ${ }^{[29]}$. The result of the cycling procedure in increasing the photocurrent is displayed in Figure 4. The cyclic polarization was continued until saturation in the cathodic photocurrent has been reached. This increase is attributed to the successive formation of a p-n junction between $\mathrm{InP}$ and a photoelectrochemically formed n-type $\ln _{2} \mathrm{O}_{3}$ that also contains phosphates and phosphites as identified in synchrotron radiation photoelectron spectroscopy ${ }^{[30]}$ see Figures 5 and 9 . With a value of about $5 \mathrm{mAcm}^{-2}$, the photocurrent density is well below that expected for white light illumination and an energy gap of $1.35 \mathrm{eV}$.

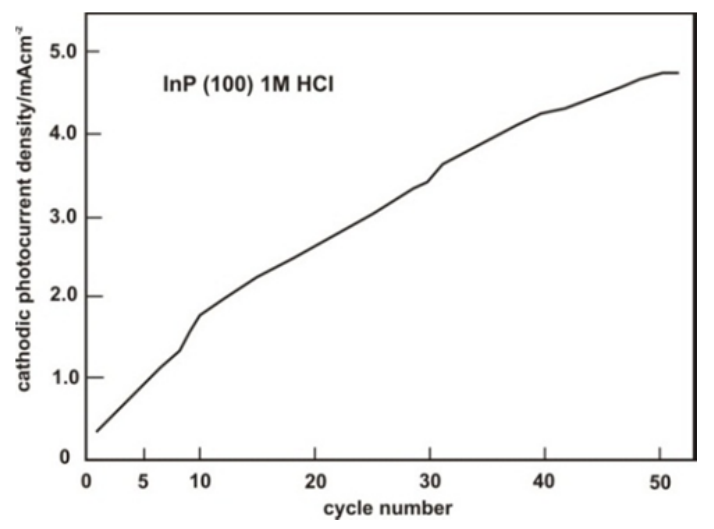

Figure 4. Influence of the cycle number on the cathodic photocurrent at the cathodic boundary of the cycling process $(-0.1 \mathrm{~V}$ vs. SCE) in $1 \mathrm{M} \mathrm{HCl}$; cycling limits: $-0.1 \mathrm{~V}$ and $+0.3 \mathrm{~V}$ (SCE).

The according energy scheme is shown in Figure 5 . It is based on the flatband potential and electron affinity of $\mathrm{p}$-InP. The scheme assumes a work function of the normal hydrogen electrode of $4.6-4.7 \mathrm{eV}$, a value that has been experimentally confirmed ${ }^{[31,32]}$. Interface states, as indicated, will alter the situation such that a partial shift of the band edges occurs. This influence has been neglected here for simplicity reasons. Also, surface dipoles are known to alter the electron affinity considerably ${ }^{[33]}$. Therefore, the presented scheme only gives a model-type background of the occurring electrochemical reactions in relation to the semiconductor band edges.

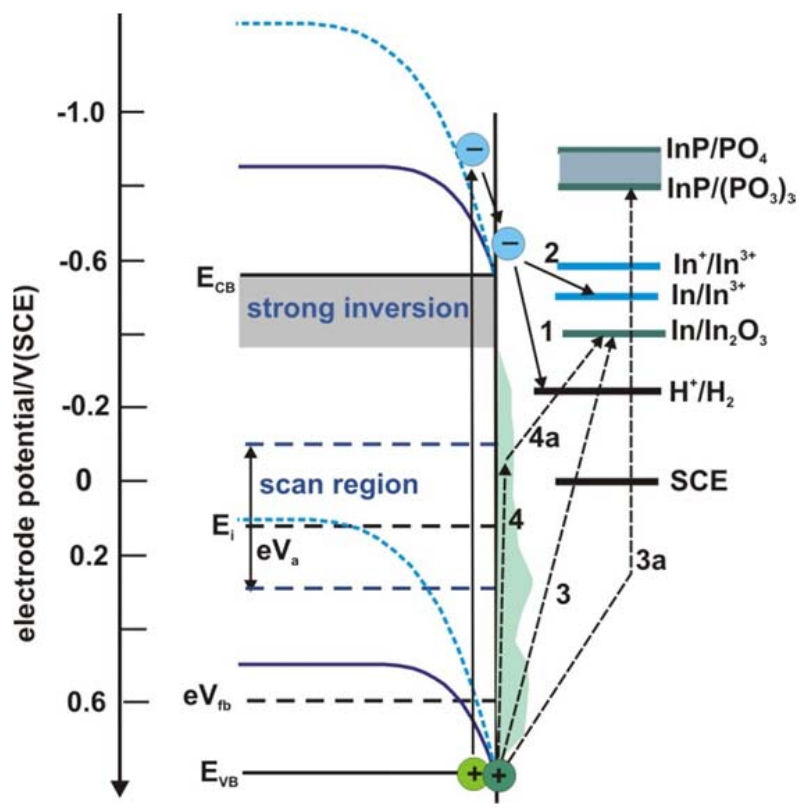

Figure 5. Energy schematic on the electronic situation at the $\mathrm{p}-\mathrm{InP} / \mathrm{HCl}$ electrolyte contact; $E_{V B}, E_{C B}$, valence band and conduction band edge; $E_{i}$ : intrinsic Fermi level; $\mathrm{eV}_{\mathrm{a}}$ : applied voltage in terms of energy; $\mathrm{eV}_{\mathrm{fb}}$ : flatband 
situation of $\mathrm{p}-\mathrm{InP}$; processes 1,2 : cathodic reactions due to excess minority electrons, (1) $\mathrm{H}_{2}$ evolution, (2) cathodic decomposition; processes 3, 4a: indium oxide formation via (3) valence band holes or $(4,4 a)$ holes from empty surface states; processes summarized under 3a: indium phosphate or phosphate formation

The composition of the anodic film formed after cycling polarization has been investigated by synchrotron radiation photoelectron spectroscopy (SRPES) ${ }^{[30]}$. The data show that the interphase consists predominantly of $\operatorname{In}_{2} \mathrm{O}_{3}$ with admixtures of $\mathrm{InPO}_{4}$ and $\operatorname{In}\left(\mathrm{PO}_{3}\right)_{3}$ as expected from the corrosion reactions in the equation above. SRPES data and transmission electron microscopy (TEM) experiments show that the interphase is about $7 \mathrm{~nm}$ thick, hence the thickness is too large to allow for tunnelling ${ }^{[34]}$. For the absorption of a substantial fraction of photons, on the other hand, the thickness is too small. Besides, the energy gap will be slightly larger due to the admixtures, reducing absorption even further. The absorbed carriers will contribute to the photocurrent since, even in highly disordered materials, minority carrier diffusion lengths are larger than the thickness of the interphase. There is no barrier for hole transport to the $\mathrm{p}-\mathrm{InP}$. The in situ fabrication of the cell is completed by photoelectrodeposition of $\mathrm{Rh}$ from a $\mathrm{Rh}$ (III) chloride solution. The choice of Rh was preceded by a comparison between $\mathrm{Pt}$, Ir and $\mathrm{Rh}$; the latter evidenced the best performance. A typical deposition protocol is shown in Figure 6.

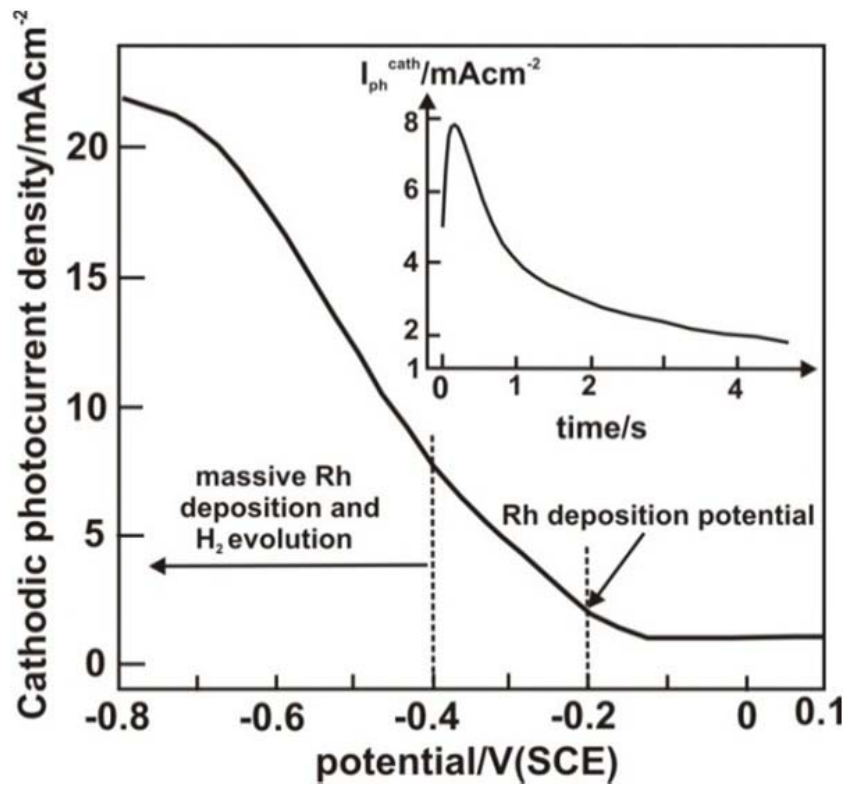

Figure 6. Overview on the conditions for light-induced Rh electrodeposition onto a p-InP surface decorated with an anodic film; the insert shows the time dependence of the deposition photocurrent density; the chosen deposition potential is indicated (see text).

Since massive Rh deposition occurred at potentials negative from $-0.4 \mathrm{~V}$, a deposition potential has been chosen such that the formed deposit is thin enough to enable the transmission of the incoming light. Therefore, a potential near the onset of the deposition reaction $(\sim-0.15 \mathrm{~V})$, e.g. $-0.2 \mathrm{~V}$, has been selected. The resulting structure shown in the TEM image in Figure 7 has been recorded after the passage of $\sim 40 \mathrm{Ccm}^{-2}$ of the device under operation at the maximum power point (compare Figure 8). Figure 7 shows (i) an interfacial film of about $7 \mathrm{~nm}$ thickness that covers the surface of InP completely, (ii) a connected Rh film that consists of 5-10 nm large particles which exhibit some crystallinity and (iii) the obvious absence of corrosion since the InP-film interface is, on the atomic level, not attacked. The same observation is made with TEM data taken on a considerably larger length scale ${ }^{[18]}$. The absence of corrosion allows quantifying the evolution of hydrogen by the transferred charge.

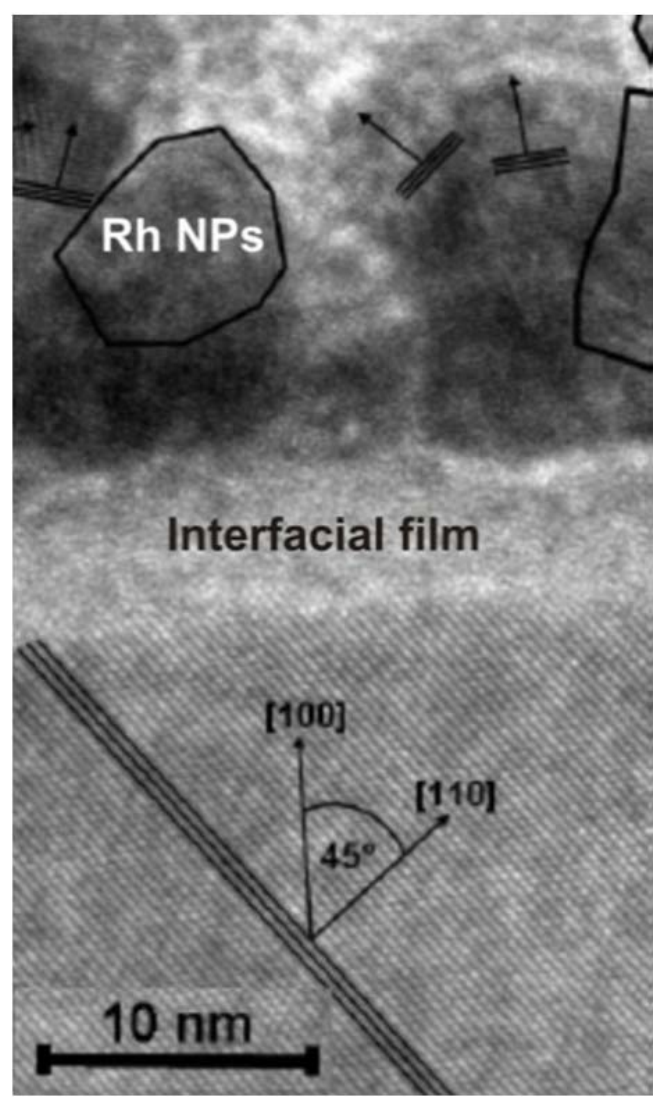

Figure 7. TEM cross sectional image of the prepared photoelectrocatalytic structure; components as indicated in the figure; note the epitaxial character of the InP substrate and the crystal planes in the Rh nanoparticles (NPs).

Comparison of Figures 7 and 8 appears to reveal a seemingly contradiction: the interfacial film is too thick to allow efficient charge transport across it but, nevertheless, the solar conversion efficiency reaches almost $14 \%$. A possible solution is provided by inspection of electron affinities $X$ of $\mathrm{InP}$ and $\mathrm{In}_{2} \mathrm{O}_{3}$ : Although the interphase does not consist of a single material, it is predominantly composed of indium oxide. For $\operatorname{InP}, \mathrm{X}=4.4 \mathrm{eV}$ and for $\ln _{2} \mathrm{O}_{3}$, the value is $4.5 \mathrm{eV}$. We hypothesize that the photoactivation process generates an interface that is n-type doped. In fact, n-type doping by hydrogen has been reported recently ${ }^{[35]}$. $\mathrm{H}$ species act as shallow donors. It is likely that $\mathrm{H}$ doping of the interface occurs in the activation process, where hydrogen evolution is one of the dominating reactions. We have observed that the interfacial film has increased slightly $(\sim 2 \mathrm{~nm})$ in thickness after the photoelectrodeposition procedure. Since we also observe a chemical $\mathrm{Rh}$ deposition reaction at the rest potential (unpublished), we assume that a hidden anodic corrosion reaction occurs simultaneously, albeit at a low rate. 


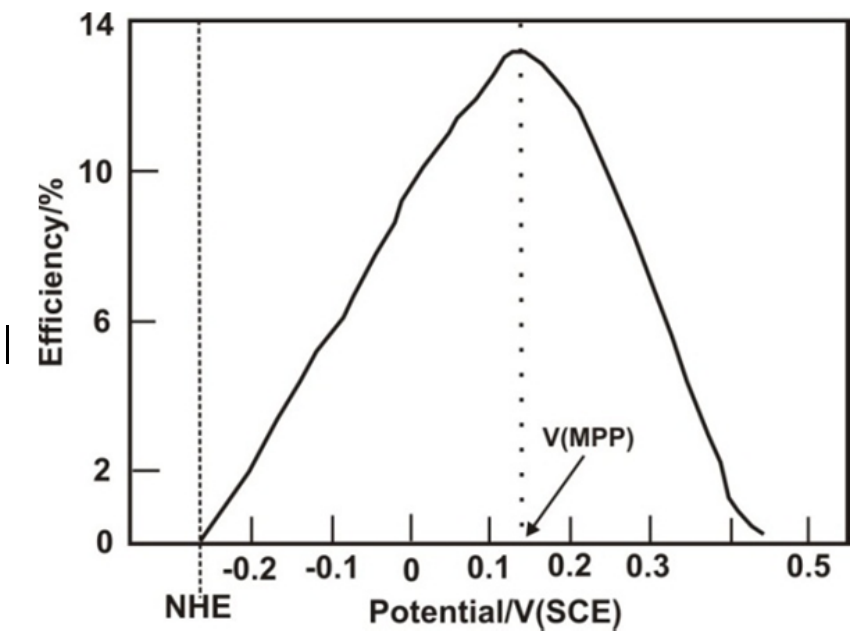

Figure 8. Output power characteristic of a $\mathrm{p}-\ln \mathrm{P}(100)$ epitaxial thin film / indium oxide-phosphate-phosphite / Rh nanoparticle photoelectrocatalytic structure; $\mathrm{V}(\mathrm{MPP})$ : voltage at the maximum power point; note the slight variations on the curve; they are mainly due to the influence of $\mathrm{H}_{2}$ bubbles on the photocurrent; illumination: $\mathrm{W}$-I lamp, light intensity $100 \mathrm{mWcm}^{-2}$.

The resulting proposed energy band diagram is shown in Figure 9. It assumes uninhibited transport via the conduction band of the interfacial film and a buried $\mathrm{p} / \mathrm{n}$ junction that has been formed in-situ by photoelectrochemical processing. This junction moves the photovoltaically active region away from the reactive electrolyte contact and makes the contact potential difference independent from the electrolytic conditions. The photovoltage obtained is therefore dependent on the contact potential difference between $\mathrm{n}$-type indium oxide/phosphate/phosphate and $\mathrm{p}-\operatorname{InP}$. Hot electrons, generated in the $\operatorname{InP}$ absorber can be transported ballistically within the interface conduction bands above the conduction band edge since the film is thin enough to allow unscattered carrier transport.

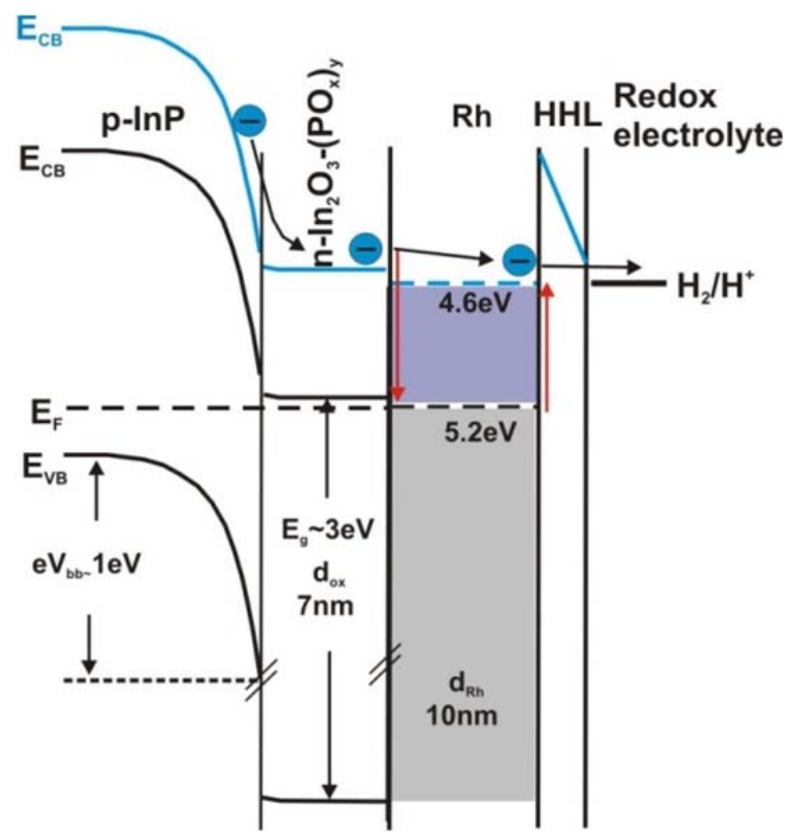

Figure 9. Postulated energy band diagram for the in-situ formed InP-based photoactive structure; HHL: Helmholtz layer, all other abbreviations as in the above figures; red arrows: band edge shifts (see text).
The arrows in Figure 9 indicate band edge shifts: Since the work function of $\mathrm{Rh}$ is about $5.2 \mathrm{eV}$, the formed $\mathrm{InP} /$ indium oxidic phase junction will equilibrate with the metal Fermi level. Thus, the band edges shift downward (see red arrow at this junction). Upon contact with the redox electrolyte, the complete system, due to the full coverage with the metal film, will equilibrate with the "solution Fermi level". This results in an upward band edge shift (see second red arrow) and a corresponding potential drop in the Helmholtz layer on top of the metal.

The above scheme in Figure 9 is based on SRPES data, in particular XPS valence band spectroscopy that is typically used in determining band offsets between ultrathin films and substrates ${ }^{[30]}$. It explains the successive cathodic photocurrent increase as well as the levelling of the current after about 50 cycles. The latter indicates that enough thickness of the interfacial film has been reached to form a $p-n$ junction with the full contact potential difference.

\section{Analogy between $\operatorname{InP}(100)$ and $\mathrm{GaP}(100)$ surface structures}

Regarding surface structure, reconstruction, and termination as well as MOVPE preparation condition, $\operatorname{InP}(100)$ and $\mathrm{GaP}(100)$ are very closely related to each other. We investigated the electronic structure of both III-rich and P-rich surfaces of $\operatorname{InP}(100)$ and $\mathrm{GaP}(100)$ substrates by two photon photoemission (2PPE) spectroscopy. In contrast to standard photoemission techniques, 2PPE addresses both occupied and unoccupied electronic states. The acquisition of the 2PPE spectra without time resolution (as shown in Figure 10) requires only a single fs laser beam to be focused on the surface of the sample. The excitation of electrons above the vacuum level occurs either in a direct coherent twophoton-transition from occupied states or in a two-step process involving intermediate states above the Fermi-level.

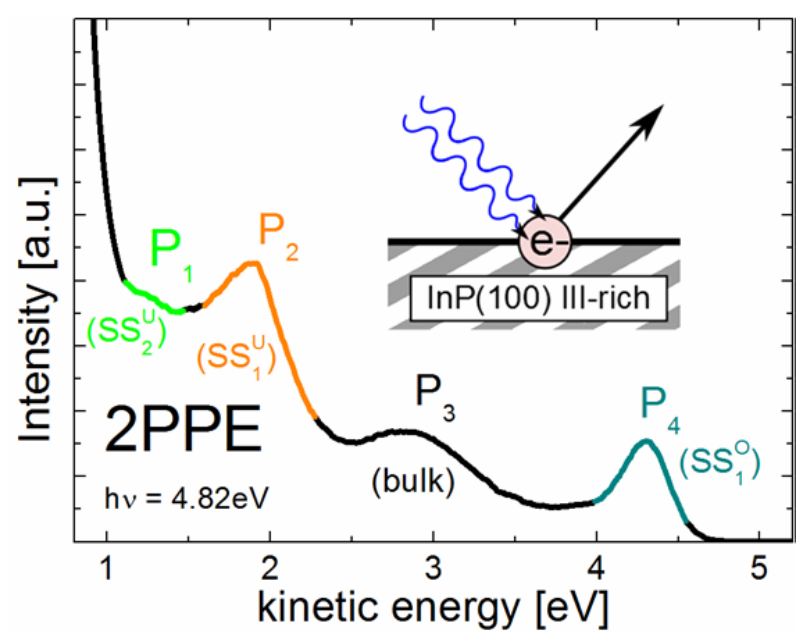

Figure 10. Single-beam 2PPE spectrum of the III-rich $\operatorname{InP}(100)$ surface $(4.82 \mathrm{eV}$ incident photon energy). The inset sketches the underlying two-photon photoemission process. The observed peaks are labeled $P_{1}$ to $P_{4}$ in energetic order. The corresponding surface states are indicated as $\mathrm{SS}_{1}{ }^{\mathrm{U}}, \mathrm{SS}_{2}{ }^{\mathrm{U}}$, and $\mathrm{SS}_{1}{ }^{\mathrm{O}}$, where the upper superscript indices distinguish between occupied $(\mathrm{O})$ and unoccupied $(U)$ states.

Figure 10 shows a 2PPE spectrum of a III-rich $\operatorname{lnP}(100)$ surface measured with $257 \mathrm{~nm}$ laser pulses (4.82 eV photon energy), where the photoelectron intensity is plotted over their kinetic energy. Further experiments enable the assignment of observed peaks (labeled P1 - P4) to electronic features of the 
band structure (Figure 11). Regarding III-rich $\operatorname{InP}(100)$, exposure to excited molecular hydrogen $\left(\mathrm{H} 2^{*}\right)$ established a relation of peaks $\mathrm{P} 1, \mathrm{P} 2$, and $\mathrm{P} 4$ with surface states, while $\mathrm{P} 3$ was identified as bulk related feature ${ }^{[36]}$. Variation of the incident photon energy showed that $\mathrm{P} 1$ and $\mathrm{P} 2$ arise due to a transition involving intermediate electronic states +0.25 and $+0.85 \mathrm{eV}$ above the conduction band maximum (CBM), respectively. In contrast, P4 is associated with a coherent two-photon transition from an occupied surface state $0.1 \mathrm{eV}$ below the valence band minimum (VBM).

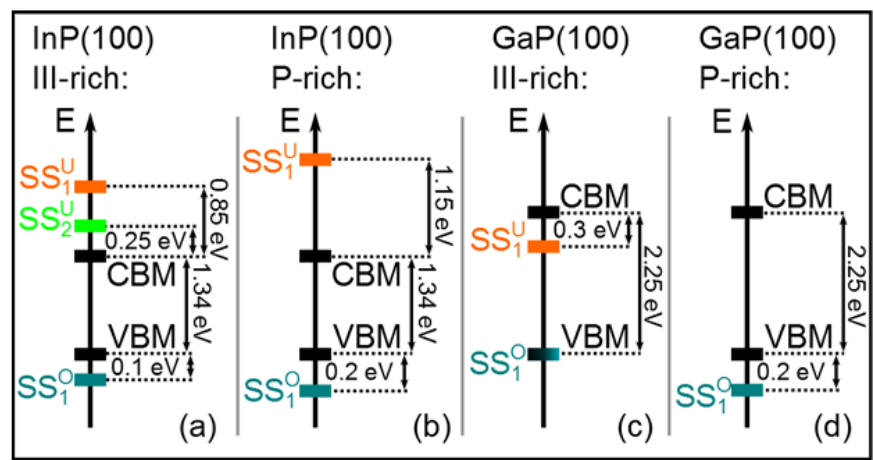

Figure 11. Schematic diagram of the energetic position of III- $(a, c)$ and P-rich $(b, d) \ln P(100)(a, b)$ and $\operatorname{GaP}(100)(c, d)$ surface states determined by $2 \mathrm{PPE}$ in relation to the valence and conduction band edges (in arbitrary scale).

The schematic band structure diagram in Figure 11 summarizes the 2PPE results for III-rich $\operatorname{InP}(100)$ (a) and shows our findings established by analogue experiments with $P$-rich $\ln \mathrm{P}(100)(\mathrm{b})$ as well as with the closely related III-rich (c) and $\mathrm{P}$ rich prepared surfaces of $\mathrm{GaP}(100)$. While a detailed report on the latter 2PPE data and their evaluation is in preparation, the comparison of the comprised findings shows distinct differences and similarities of the electronic structures between those surfaces: An occupied surface state close to the VBM was observed for all sample types with only slightly different energetic positions. In contrast, the results differed significantly regarding unoccupied surface states. Only for P-rich $\mathrm{GaP}(100)$, none were observed, while the 2PPE spectra of all other surface reconstructions contained unambiguous signatures for unoccupied surface states at very different energetic positions relative to the CBM. Since the surface reconstruction mechanisms of $\operatorname{InP}(100)$ and $\mathrm{GaP}(100)$ are identical, the discrepancy might rather be related to the difference of the bulk electronic.
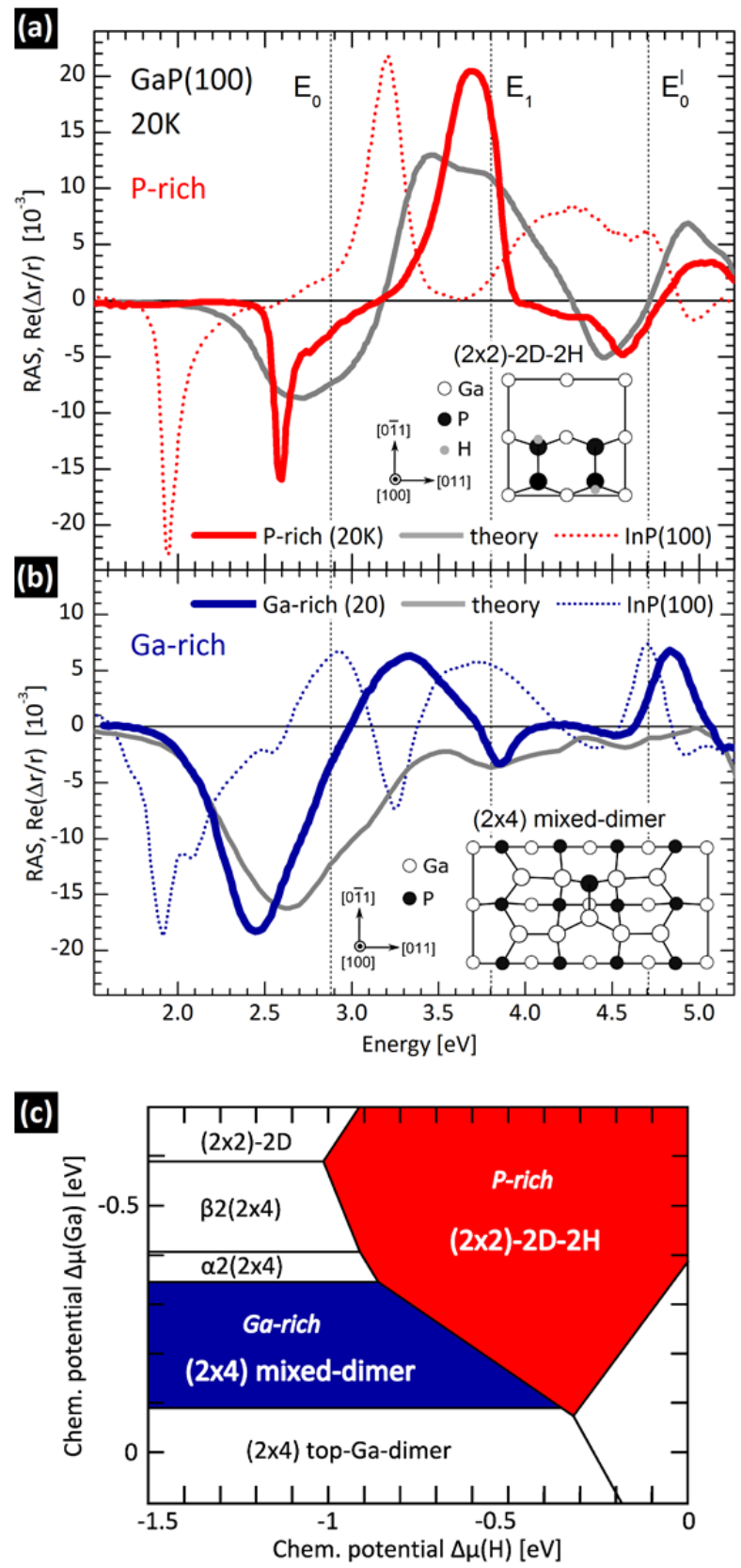

Figure 12. Comparison of theoretical RA spectra for (a) P-rich ${ }^{[37]}$ and (b) III-rich ${ }^{[38]}$ surfaces of $\mathrm{GaP}(100)$ to experimental data obtained at $20 \mathrm{~K}$ also for $\ln \mathrm{P}(100)$ [39]. (c) Calculated phase diagram of the hydrogen exposed $\mathrm{GaP}(100)$ surfaces after Ref. ${ }^{[37]}$, where $\Delta \mu(\mathrm{H})$ is given with respect to molecular hydrogen. Colored areas identify surface reconstructions relevant for this study: the P-rich configuration typical for MOVPE preparation (red) and the Ga-rich mixed-dimer surfaces prepared by annealing without TBP supply (blue).

The structural analogy between both III-rich and P-rich surface reconstructions of $\operatorname{InP}(100)$ and $\operatorname{GaP}(100)$ is also reflected by the similarity of the characteristic RA spectra of those surfaces shown in Figure 12. The theoretical spectrum according to the mixed dimer model of Schmidt and coworkers ${ }^{[38]}$ is included (grey line). While the calculated spectra agree fairly well with the experimental data, the direct identification from theory only is not sufficiently reliable. Since small variations in the atomic order of the surface ${ }^{[28][40][41]}$ or just a change of the sample temperature [42] influence RA spectra significantly, all contributions to the signal must be considered precisely to avoid misinterpretations. In direct analogy to the results shown in Figure 
3, in situ RAS enables precise and reliable control over the MOVPE preparation of III-rich and P-rich $\mathrm{GaP}(100)$ surfaces.

Both methods, RAS and 2PPE, which have been employed here, are highly sensitive to surface states. While it has been shown that prominent features in RA spectra are strongly related to anisotropic transitions between occupied and unoccupied surface states ${ }^{[37]}$, 2PPE allows studying occupied and unoccupied states independently. Nevertheless, a direct investigation of resonant transitions between surface states with 2PPE, by using an additional pump-beam, which is tuned resonant to the energy of possible inter surface state transitions might give additional information about the nature of the RA spectra.

\section{Gallium phosphide heteroepitaxy on silicon}

In contrast to other III-V compound semiconductors, gallium phosphide is almost lattice matched to silicon enabling the growth of relatively thick pseudomorphic films ${ }^{[43]}$ before the accumulated strain enforces lattice relaxation by the formation of misfit dislocations. Hence, GaP/Si(100) heteroepitaxy represents an ideal III-V/Si(100) model system ${ }^{[44]}$ for the investigation of issues related to the polar on non-polar interface in the absence of other defect mechanisms related to the differences in lattice constants and thermal expansion coefficients. Beyond their importance for fundamental III-V/Si(100) research, well-ordered heteroepitaxial $\mathrm{GaP} / \mathrm{Si}(100)$ surfaces serve as template for lattice matched III-V integration based on suitable dilute nitride materials (Figure 3 ). Incorporation of even small nitrogen concentrations induces a transition to a direct-like band gap as well as a decrease of the band gap energy.

The epitaxial challenges of the crucial III-V/Si heterojunction ${ }^{[15]}$ are based on differences in general material parameters as well as the complex formation of the heterovalent (polar-on-nonpolar) interface:

I. lattice mismatch leading to misfit dislocations,,

II. different thermal expansion causing strain after growth,

III. interdiffusion inducing undesired cross-doping,

IV. polarity of the interface violating the charge neutrality,

V. anti-phase disorder involving anti-phase boundaries.

Although both crystal structures and lattice constants are very similar, zinc blende $\mathrm{GaP}$ exhibits a reduced symmetry to diamond Si. While $\operatorname{GaP}(100)$ surfaces always form double layer steps, also single layer steps occur on $\mathrm{Si}(100)$ substrates ${ }^{[45]}$. Figure 13 shows STM and LEED results of a typical Si(100) surface prepared by MOVPE. Equivalent half-order LEED spots indicate the presence of two mutually perpendicular surface reconstruction domains, while the STM image shows the switching of the dimer orientation at single-layer surface steps.

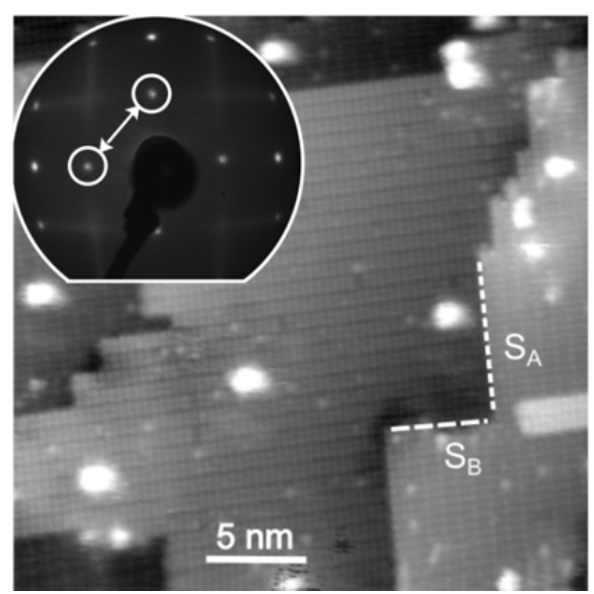

Figure 13. STM image and LEED pattern of MOVPE prepared Si(100) surface.

During III-V nucleation, single-layer steps on the $\mathrm{Si}(100)$ substrate initiate the formation of anti-phase boundaries (APBs) [46]. The undesirable anti-phase disorder may be suppressed either by double-layer step formation on the $\mathrm{Si}(100)$ substrate or by pair wise self-annihilation of APBs during growth of the GaP layer ${ }^{[47]}$. Direct evidence for anti-phase domains (APDs) as a bulk feature can be gained from X-ray scattering ${ }^{[15]}$ and highresolution TEM images ${ }^{[48]}$. Low-energy electron microscopy (LEEM) enables destruction-free APD imaging on III-V/Si(100) surfaces ${ }^{[49]}$. Reduced binding energies and strain induce trench formation along APBs during anisotropic etching or thermal annealing enabling ex situ quantification by AFM ${ }^{[50]}$.

Rotation of anisotropic structures by $90^{\circ}$ leads to RA spectra with opposite sign enabling destruction-free in situ quantification of anti-phase disorder: The amplitude of the RA signal of P-rich $\mathrm{GaP} / \mathrm{Si}(100)$ corresponds to the APD content at the surface ${ }^{[44]}$ and can be quantified by scaling to a single-domain reference. Correction of the RA spectra regarding interference due to internal reflection at the heterointerface in combination with a homoepitaxial $\mathrm{GaP}(100)$ reference sample ${ }^{[43]}$ enables precise in situ APD quantification. Dielectric modeling of RAS data provides experimental access to the $\mathrm{GaP} / \mathrm{Si}(100)$ heterointerface ${ }^{[51]}$.

\section{GaP/Si(100) electrochemistry}

First electrochemical studies of anodic processes on GaP single crystal electrodes date back more than 40 years ${ }^{[52]}$ and discuss the anodic dissolution of $\mathrm{GaP}(111)$ in acid and alkaline solutions. Madou et al. [53] already indicate the potential of $\mathrm{GaP}$ photocathodes and report on a stabilization of $\mathrm{GaP}(111)$ surfaces in aqueous electrolytes. P-type doped $\mathrm{GaP}$ photocathodes have been used in water splitting cells, i.e. incombination with $n-\mathrm{TiO}_{2}$ [54]. Mainly due to the unsuitable band gap of the employed semiconductors for the adaption to the solar spectrum (criterion I) only low efficiencies in the range of $\eta \approx 0.25 \%{ }^{[54]}$ have been achieved so far.

The photoanodic dissolution of $\mathrm{GaP}[52,53]$ in acidic environment is

$$
\mathrm{GaP}+6 \mathrm{p}^{+}+3 \mathrm{H}_{2} \mathrm{O} \rightarrow \mathrm{Ga}^{3+}+\mathrm{H}_{3} \mathrm{PO}_{3}+3 \mathrm{H}^{+},
$$

while the cathodic reaction competing with the evolution of hydrogen is 
$\mathrm{GaP}+3 \mathrm{e}^{-}+3 \mathrm{H}^{+} \rightarrow \mathrm{Ga}+\mathrm{PH}_{3}$

While the surface of $\mathrm{GaP}$ is oxidized in aqueous solutions, the surface is reduced to states of unknown composition during cathodic voltammetric sweeps ${ }^{[55]}$. The initial surface morphology and band edges of GaP strongly depend on the chemical etching procedure, which the surface has undergone before immersion into the electrolyte: Ref. ${ }^{[56]}$ reports about a spread of band edge potentials of $700 \mathrm{mV}$. Surface defects such as dislocations play an important role for the stability of the electrode against anodic dissolution starting at such imperfections ${ }^{[57]}$. The exact electronic configuration of $\mathrm{GaP}$ surfaces that were wet-chemically etched still needs clarification ${ }^{[56]}$. This knowledge is essential for the design of appropriate interfaces and could be resolved by investigations, where the electrode material is brought into the electrolyte directly after growth or (UHV-based) characterization in a well-defined state.

Electrodeposition of a monolayer of different metals on $\mathrm{GaP}$ electrodes ${ }^{[58]}$ induces an extension of the spectral response as well as an increase of current density. Further investigations revealed an improved hydrogen production rate as well as enhanced stability especially by adsorption of Ru(III) ${ }^{[59]}$. However, hydrogen penetrates into the near-surface bulk [60] creating recombination centers, an effect even accelerated by deposited ruthenium. We conducted preliminary experiments on V-rich $\mathrm{GaP}(100)$ and $\mathrm{Ga} \mathrm{P}_{0.98} \mathrm{~N}_{0.02}$ electrodes grown by a MOVPE process on $\mathrm{Si}(100)$ substrates ${ }^{[43]}$ and similarly to the established InP preparation described above. Figure 14 shows cyclic voltammograms of a $\mathrm{GaP} / \mathrm{Si}(100)$ electrode which was contacted via the Si backside and cyclically polarized in $0.5 \mathrm{M} \mathrm{HCl}$ at a scan rate of $10 \mathrm{mV} / \mathrm{s}$, similar to the treatment of $\mathrm{InP}$. A characteristic current peak (inset Figure 14) appears around a potential of -0.73 $\checkmark$ vs. $\mathrm{SCE}$, both in $\mathrm{HCl}$ and in $1 \mathrm{M} \mathrm{H}_{2} \mathrm{SO}_{4}$.

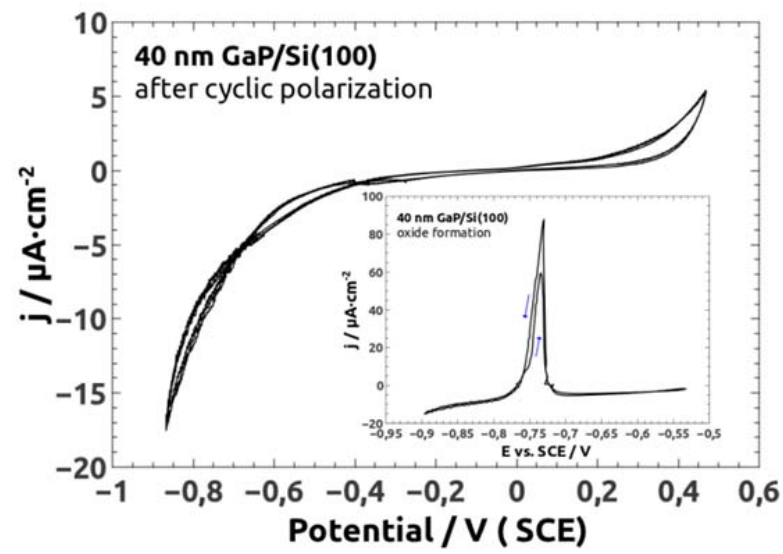

Figure 14. Cyclic voltammogram of $40 \mathrm{~nm} \mathrm{GaP}$ on $\mathrm{Si}(100)$ in $0.5 \mathrm{M} \mathrm{HCl}$ after oxide formation (10 $\mathrm{mV} / \mathrm{s}$, without light). Inset shows the current peak ascribed to the formation of an oxide layer.

The feature shown in the inset of Figure 14 has been assigned to the formation of a $\mathrm{Ga}(\mathrm{OH})_{3}$ surface passivation layer [53]. We suppose that the difference of the energetic level is caused (a) by different surface orientations and (b) by a different surface treatment, which both might induce significant shifts ${ }^{[56]}$. After several periodic cycles through this potential range, the observed peak finally disappeared completely, and we observed a mainly diode-like behavior (Figure 14).
Dilute nitride III-V growth lattice matched to Si(100)

The incorporation of $\mathrm{N}$ in GaP has a significant influence on the electronic structure. Regarding the solar absorption efficiency, two aspects are of particular interest: nitrogen incorporation (i) decreases the band gap dramatically (Figure 2), (ii) changes the indirect band gap of $\mathrm{GaP}$ to a direct-like one for diluted nitride $\mathrm{GaP}_{1-x} \mathrm{~N}_{\mathrm{x}}$ with $\mathrm{x} \geq 0.5 \%{ }^{[61]}$, and (iii) attenuates the temperature dependence of the band gap ${ }^{[62]}$.

A dilute nitride $\mathrm{GaPN} / \mathrm{Si}(100)$ tandem absorber structure may solve the undesirable trade-off between a high band gap to provide sufficient voltage (criterion II) versus a low one to utilize the solar spectrum efficiently (criterion I). The ternary compound GaPN as top cell on a Si bottom cell would already reach a limiting efficiency of about $37 \%$. The desirable optimum value of about $45 \%$ requires a material combination providing band gaps of $1.7 \mathrm{eV}$ and $1.1 \mathrm{eV}$ for the top and the bottom cell, respectively. The $\mathrm{Si}(100)$ substrate directly matches with the lower band gap, and further incorporation of nitrogen balanced by arsenic or indium allows to reduce the band gap energy of the GaPNAs material system while maintaining the lattice constant of $\mathrm{Si}(100)$.

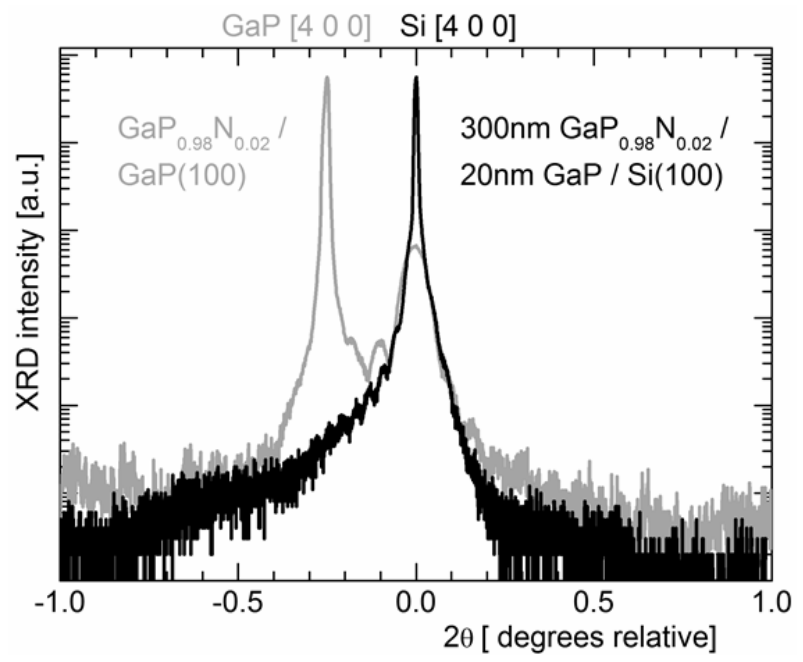

Figure 15. XRD rocking curve around the Si $\left[\begin{array}{lll}0 & 0 & 4\end{array}\right]$ reflex comparing the growth of dilute nitride on a $\mathrm{GaP}(100)$ and $\mathrm{Si}(100)$ substrates.

Beyond that, a dilute nitride incorporation level of $x=2 \%$ yields a III-V compound lattice matched to silicon as evidenced by X-ray diffraction (XRD) shown in Figure 15. The quarternary GaPNAs material system enables further reduction of the bandgap while maintaining the lattice-match to $\mathrm{Si}(100)$, since additional nitrogen incorporation can be balanced by adequate As concentrations. The challenge of this approach is to maintain a homogenously high crystal quality. The incorporation of nitrogen is according to Deutsch et al. ${ }^{[63]}$ beneficial for the stability of the semiconductor in the electrolyte, while arsenic seems to be prone to dissolution in acids or bases.

A detailed analysis of GaPN growth parameters using UDHMy (1.1-dimethylhydrazine) is given in Ref. Kunert and coworkers ${ }^{[64]}$. Geisz et al. presented the first GaPNAs tandem solar cell lattice matched to silicon ${ }^{[65]}$, where the efficiency was limited to about $5 \%$ due to the insuffient performance of the GaPNAs top cell and non-ideal tunneling diodes. Also unintentional carbon incorporation has been reported ${ }^{[6]}$. 


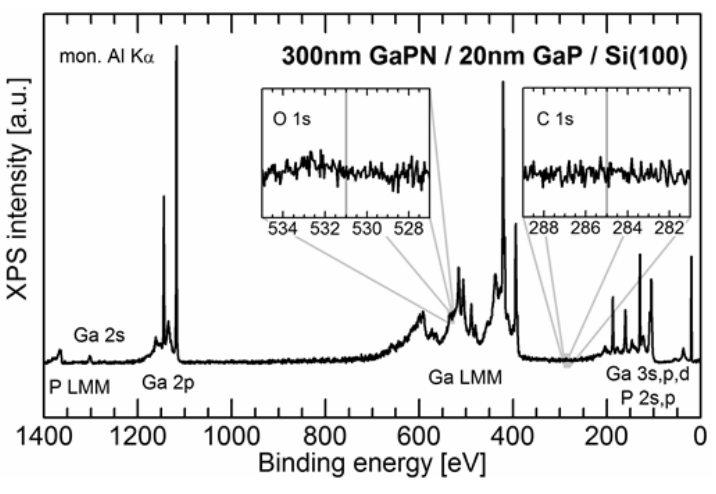

Figure 16. Overview XP spectrum of $\mathrm{GaPN} / \mathrm{GaP} / \mathrm{Si}(100)$, the insets show the $\mathrm{O} 1 \mathrm{~s}$ and $\mathrm{C} 1 \mathrm{~s}$ photoemission line, respectively.

After contamination-free transfer from MOVPE to UHV, XP spectra of a $300 \mathrm{~nm} \mathrm{GaP}{ }_{0.98} \mathrm{~N}_{0.02}$ film grown on a $20 \mathrm{~nm} \mathrm{GaP}$ buffer on $\mathrm{Si}(100)$ (Figure 16) does not show any carbon contamination. The $\mathrm{Ga}$ Auger spectrum overlaps with the $\mathrm{N}$ photoemission line complicating the confirmation of the incorporated $\mathrm{N}$ content. First in situ RA spectra indicate only small influences of $\mathrm{N}$ on the surface reconstruction of $\mathrm{V}$-rich prepared $\mathrm{GaPN} / \mathrm{Si}(100)$ compared to $\mathrm{GaP} / \mathrm{Si}(100)$. Current work includes detailed surface and interface analysis directed on improving the $\mathrm{GaPN} / \mathrm{Si}(100)$ tandem absorber structure for photoelectrochemistry.

\section{Conclusion}

We propose epitaxial dilute nitride $\mathrm{GaPN} / \mathrm{Si}(100)$ tandem absorber structures for direct solar water splitting. Efficient $\ln P(100)$ photocathodes grown by MOVPE have been demonstrated. Detailed UHV characterization has confirmed welldefined atomic-scale surface properties of have been confirmed in direct analogy for both MOVPE-prepared $\operatorname{InP}(100)$ and $\mathrm{GaP}(100)$. Pseudomorphic GaP growth on $\mathrm{Si}(100)$ substrates enables high-quality III-V heteroepitaxy and provides an ideal template for the integration of lattice-matched dilute nitride GaPN and GaPNAs structures for photoelectrochemical water splitting.

\section{Experimental Section}

Epitaxial growth of P-based III-V samples for photoelectrochemistry was conducted in a horizontal MOVPE reactor (Aixtron AIX-200) on $\ln P(100), \operatorname{GaP}(100)$, and $\mathrm{Si}(100)$ substrates ${ }^{[41,67]}$. We monitored thermal substrate deoxidation, epitaxial growth, and dedicated surface preparation by in situ RAS (LayTec EpiRAS200) and benchmarked the results to STM, LEED, and XPS (SPECS Aarhus, Er-LEED, Focus500/Phoibos100) as well as to time-of-flight 2PPE spectroscopy ${ }^{[68]}$, which were accessed by a contamination-free MOVPE-to-UHV transfer system ${ }^{[39]}$. The epitaxial layers were characterized by XRD (Panalytical X'PertPro) and high-resolution TEM (Philips CM12). Prior to photoelectrochemical characterization ${ }^{[69]}$, we cleaned our III-V samples methanol bromine etching.

\section{Acknowledgements}

The authors are indebted to Peter Kleinschmidt for STM at Si(100), to Kristof Möller for in situ RAS at InP(100), and to Ulrike
Bloeck for high-resolution TEM. H.D. appreciates helpful discussions with John Turner, John Geisz, and Clemens Heske as well as financial support by an EU Marie Curie fellowship (IOF No. 300971). M.M. acknowledges financial support by Studienstiftung des Deutschen Volkes.

Keywords: water splitting · semiconductors $\cdot$ chemical vapor deposition · surface analysis · electrochemistry

[1] A. Fujishima, K. Honda Nature. 1972, 238, 37-+

[2] O. Khaselev, J. A. Turner Science. 1998, 280, 425-427.

[3] K. A. Bertness, S. R. Kurtz, D. J. Friedman, A. E. Kibbler, C. Kramer, J. M. Olson Appl. Phys. Lett. 1994, 65, 989-991.

[4] Z. B. Chen, T. F. Jaramillo, T. G. Deutsch, A. Kleiman-Shwarsctein, A. J. Forman, N. Gaillard, R. Garland, K. Takanabe, C. Heske, M. Sunkara, E. W. McFarland, K. Domen, E. L. Miller, J. A. Turner, H. N. Dinh J. Mater. Res. 2010, 25, 3-16.

[5] T. G. Deutsch, J. L. Head, J. A. Turner J. Electrochem. Soc. 2008, 155, B903-B907.

[6] A. Heller Science. 1984, 223, 1141-1148.

[7] W. Shockley, H. J. Queisser J. Appl. Phys. 1961, 32, 510-\&.

[8] B. Kaiser, W. Jaegermann, S. Fiechter, S. Lewerenz Bunsen-Magazin. 2011, 4, 104.

[9] W. Guter, J. Schone, S. P. Philipps, M. Steiner, G. Siefer, A. Wekkeli, E. Welser, E. Oliva, A. W. Bett, F. Dimroth Appl. Phys. Lett. 2009, 94, 3.

[10] G. Letay, A. W. Bett Proc. 17th EU PV Sol. En. Conf. 2001, 178.

[11] I. Vurgaftman, J. R. Meyer, L. R. Ram-Mohan J. Appl. Phys. 2001, 89, 5815-5875.

[12] S. Tiwari, D. J. Frank Appl. Phys. Lett. 1992, 60, 630-632.

[13] W. Shan, W. Walukiewicz, J. W. Ager, E. E. Haller, J. F. Geisz, D. J. Friedman, J. M. Olson, S. R. Kurtz Phys. Rev. Lett. 1999, 82, 1221-1224.

[14] I. Vurgaftman, J. R. Meyer J. Appl. Phys. 2003, 94, 3675-3696.

[15] S. F. Fang, K. Adomi, S. Iyer, H. Morkoc, H. Zabel, C. Choi, N. Otsuka J. Appl. Phys. 1990, 68, R31-R58.

[16] H. Soda, K. Iga, C. Kitahara, Y. Suematsu Jpn. J. Appl. Phys. 1979, 18, 2329-2330.

[17] B. E. Sagol, U. Seidel, N. Szabo, K. Schwarzburg, T. Hannappel Chimia. 2007, 61, 775-779.

[18] H. J. Lewerenz, C. Heine, K. Skorupska, N. Szabo, T. Hannappel, T. VoDinh, S. A. Campbell, H. W. Klemm, A. G. Munoz Energy \& Environmental Science. 2010, 3, 748-760.

[19] T. Hannappel, S. Visbeck, M. Zorn, J. T. Zettler, F. Willig Journal of Crystal Growth. 2000, 221, 124-128.

[20] A. M. Frisch, P. Vogt, S. Visbeck, T. Hannappel, F. Willig, W. Braun, W. Richter, J. Bernholc, W. G. Schmidt, N. Esser Applied Surface Science. 2000, 166, 224-230.

[21] L. Töben, L. Gundlach, R. Ernstorfer, R. Eichberger, T. Hannappel, F. Willig, A. Zeiser, J. Forstner, A. Knorr, P. H. Hahn, W. G. Schmidt Phys. Rev. Lett. 2005, 94.

[22] W. G. Schmidt, P. H. Hahn, F. Bechstedt, N. Esser, P. Vogt, A. Wange, W. Richter Phys. Rev. Lett. 2003, 90, 4.

[23] P. Vogt, T. Hannappel, S. Visbeck, K. Knorr, N. Esser, W. Richter Phys. Rev. B. 1999, 60, R5117-R5120.

[24] P. Kleinschmidt, H. Döscher, P. Vogt, T. Hannappel Phys. Rev. B. 2011 83, 155316.

[25] R. F. C. Farrow J. Phys. D-Appl. Phys. 1974, 7, 2436-2448.

[26] W. G. Schmidt, F. Bechstedt, N. Esser, M. Pristovsek, C. Schultz, W. Richter Phys. Rev. B. 1998, 57, 14596-14599.

[27] N. Esser, U. ReschEsser, M. Pristovsek, W. Richter Phys. Rev. B. 1996, 53, 13257-13259.

[28] T. Letzig, H. J. Schimper, T. Hannappel, F. Willig Phys. Rev. B. 2005, 71, 4.

[29] K. H. Schulte, H. J. Lewerenz Electrochim. Acta. 2002, 47, 2633-2638.

[30] A. G. Munoz, C. Heine, H. W. Klemm, T. Hannappel, N. Szabo, H.-J. Lewerenz ECS Transactions. 2011, 35, 141-150.

[31] W. N. Hansen, D. M. Kolb J. Electroanal. Chem. 1979, 100, 493-500.

[32] H. J. Lewerenz Chem. Soc. Rev. 1997, 26, 239-246.

[33] M. Sander, W. Jaegermann, H. J. Lewerenz Journal of Physical Chemistry. 1992, 96, 782-790.

[34] S. M. Sze, Semiconductor devices, Wiley, New York u.a., 1985. 
[35] S. Limpijumnong, P. Reunchan, A. Janotti, C. G. Van de Walle Phys Rev. B. 2009, 80.

[36] L. Töben, T. Hannappel, R. Eichberger, K. Moller, L. Gundlach, R. Ernstorfer, F. Willig Journal of Crystal Growth. 2003, 248, 206-210.

[37] P. H. Hahn, W. G. Schmidt, F. Bechstedt, O. Pulci, R. Del Sole Phys. Rev. B. 2003, 68, 033311.

[38] W. G. Schmidt, N. Esser, A. M. Frisch, P. Vogt, J. Bernholc, F. Bechstedt, M. Zorn, T. Hannappel, S. Visbeck, F. Willig, W. Richter Phys. Rev. B. 2000, 61, 16335-16338.

[39] T. Hannappel, S. Visbeck, L. Toben, F. Willig Review of Scientific Instruments. 2004, 75, 1297-1304.

[40] L. Töben, T. Hannappel, K. Moller, H. J. Crawack, C. Pettenkofer, F. Willig Surf. Sci. 2001, 494, L755-L760.

[41] H. Döscher, K. Möller, T. Hannappel Journal of Crystal Growth. 2011, 318, 372-378

[42] S. Visbeck, T. Hannappel, M. Zorn, J. T. Zettler, F. Willig Phys. Rev. B. 2001, 63

[43] H. Döscher, T. Hannappel J. Appl. Phys. 2010, 107, 123523.

[44] H. Döscher, T. Hannappel, B. Kunert, A. Beyer, K. Volz, W. Stolz Appl. Phys. Lett. 2008, 93, 172110.

[45] H. Döscher, P. Kleinschmidt, T. Hannappel Applied Surface Science. 2010, 257, 574-580.

[46] H. Kroemer Journal of Crystal Growth. 1987, 81, 193-204.

[47] I. Nemeth, B. Kunert, W. Stolz, K. Volz Journal of Crystal Growth. 2008 310, 1595-1601.

[48] J. M. Zhou, H. Chen, F. H. Li, S. Liu, X. B. Mei, Y. Huang Vacuum. 1992, 43, 1055-1057.

[49] H. Döscher, B. Borkenhagen, G. Lilienkamp, W. Daum, T. Hannappe Surface Science Letters. 2011, 605, L38.

[50] H. Döscher, B. Kunert, A. Beyer, O. Supplie, K. Volz, W. Stolz, T Hannappel Journal of Vacuum Science \& Technology B. 2010, 28 C5H1-C5H6.

[51] O. Supplie, T. Hannappel, M. Pristovsek, H. Döscher Physical Review B 2012, in press.

[52] R. Memming, G. Schwandt Electrochim. Acta. 1968, 13, 1299-1310.

[53] M. J. Madou, F. Cardon, W. P. Gomes Berichte der Bunsengesellschaft für physikalische Chemie. 1977, 81, 1186-1190

[54] A. J. Nozik Appl. Phys. Lett. 1976, 29, 150-153.

[55] B. Smandek, H. Gerischer Electrochim. Acta. 1985, 30, 1101-1107.
[56] J. Mukherjee, B. Erickson, S. Maldonado J. Electrochem. Soc. 2010, 157, $\mathrm{H} 487$.

[57] A. Etcheberry, J. Lou Sculfort, A. Marbeuf Solar Energy Materials. 1980, 3, 347-355.

[58] H. Yoneyama, S. Mayumi, H. Tamura J. Electrochem. Soc. 1978, 125, 68-74.

[59] M. P. Dare-Edwards, A. Hamnett, J. B. Goodenough Journal of Electroanalytical Chemistry and Interfacial Electrochemistry. 1981, 119, 109-123.

[60] J. Li, R. Peat, L. M. Peter Journal of Electroanalytical Chemistry and Interfacial Electrochemistry. 1984, 165, 41-59.

[61] H. P. Xin, C. W. Tu, Y. Zhang, A. Mascarenhas Appl. Phys. Lett. 2000 76, 1267-1267.

[62] G. Y. Rudko, I. A. Buyanova, W. M. Chen, H. P. Xin, C. W. Tu Appl. Phys. Lett. 2002, 81, 3984-3986.

[63] T. G. Deutsch, C. A. Koval, J. A. Turner J. Phys. Chem. B. 2006, 110, 25297-25307.

[64] B. Kunert, J. Koch, T. Torunski, K. Volz, W. Stolz Journal of Crystal Growth. 2004, 272, 753-759.

[65] J. F. Geisz, J. M. Olson, D. J. Friedman, K. M. Jones, R. C. Reedy, M. J. Romero in Lattice-matched GaNPAs-on-silicon tandem solar cells, Vol., leee, New York, 2005, pp.695-698.

[66] J. F. Geisz, R. C. Reedy, B. M. Keyes, W. K. Metzger Journal of Crystal Growth. 2003, 259, 223-231.

[67] H. Döscher, S. Brückner, T. Hannappel Journal of Crystal Growth. 2011, 318, 563-569.

[68] L. Gundlach, R. Ernstorfer, E. Riedle, R. Eichberger, F. Willig Appl Phys B-Lasers O. 2005, 80, 727-731.

[69] K. Skorupska Journal of Solid State Electrochemistry. 2008, 13, 205-218.

Received: ((will be filled in by the editorial staff))

Published online: ((will be filled in by the editorial staff)) 